\title{
Improvement of Fermi-Level Pinning and Contact Resistivity in Ti/Ge Contact Using Carbon Implantation
}

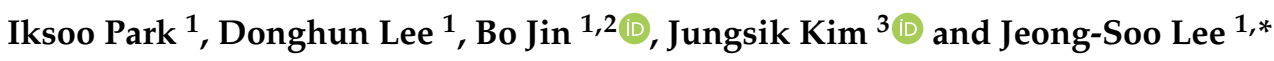 \\ 1 Department of Electrical Engineering, Pohang University of Science and Technology (POSTECH), Pohang 37673, \\ Korea; isparkk@postech.ac.kr (I.P.); leedh009@postech.ac.kr (D.L.); shengzhi86@postech.ac.kr (B.J.) \\ 2 Research and Development Department, Innovative General Electronic Sensor Technology Co., Ltd. (IGEST), \\ Pohang 37673, Korea \\ 3 Department of Electrical Engineering, Gyeongsang National University, Jinju 52828, Korea; jungsik@gnu.ac.kr \\ * Correspondence: ljs6951@postech.ac.kr
}

Citation: Park, I.; Lee, D.; Jin, B.; Kim, J.; Lee, J.-S. Improvement of Fermi-Level Pinning and Contact Resistivity in Ti/Ge Contact Using Carbon Implantation. Micromachines 2022, 13, 108. https://doi.org/ $10.3390 / \mathrm{mi13010108}$

Academic Editors: Hocheon Yoo and Joohoon Kang

Received: 16 December 2021

Accepted: 8 January 2022

Published: 10 January 2022

Publisher's Note: MDPI stays neutral with regard to jurisdictional claims in published maps and institutional affiliations.

Copyright: (C) 2022 by the authors. Licensee MDPI, Basel, Switzerland. This article is an open access article distributed under the terms and conditions of the Creative Commons Attribution (CC BY) license (https:// creativecommons.org/licenses/by/ $4.0 /)$.

\begin{abstract}
Effects of carbon implantation (C-imp) on the contact characteristics of $\mathrm{Ti} / \mathrm{Ge}$ contact were investigated. The C-imp into Ti/Ge system was developed to reduce severe Fermi-level pinning (FLP) and to improve the thermal stability of Ti/Ge contact. The current density $(J)$-voltage $(V)$ characteristics showed that the rectifying behavior of Ti/Ge contact into an Ohmic-like behavior with C-imp. The lowering of Schottky barrier height (SBH) indicated that the C-imp could mitigate FLP. In addition, it allows a lower specific contact resistivity $\left(\rho_{c}\right)$ at the rapid thermal annealing (RTA) temperatures in a range of $450-600{ }^{\circ} \mathrm{C}$. A secondary ion mass spectrometry (SIMS) showed that $\mathrm{C}$-imp facilitates the dopant segregation at the interface. In addition, transmission electron microscopy (TEM) and electron energy loss spectroscopy (EELS) mapping showed that after RTA at $600{ }^{\circ} \mathrm{C}, \mathrm{C}$-imp enhances the diffusion of Ge atoms into Ti layer at the interface of Ti/Ge. Thus, carbon implantation into Ge substrate can effectively reduce FLP and improve contact characteristics.
\end{abstract}

Keywords: MS contact; fermi-level pinning; titanium; germanide; carbon; implantation

\section{Introduction}

As a channel material for the next-generation field-effect transistors (FETs), Germanium $(\mathrm{Ge})$ is considered a promising alternative to silicon $(\mathrm{Si})$ owing to its higher carrier mobility and the process compatibility with the advanced Si microfabrication. However, the low-solid solubility and the high-diffusion coefficient of n-type dopants in Ge hinder the realization of low specific contact resistivity $\left(\rho_{c}\right)$ [1]. Moreover, Fermi-level pinning (FLP) caused by the metal-induced gap states (MIGS) at the metal/Ge interface is another problem to be solved [2-5]. FLP strongly occurs near the Ge valence band $\left(E_{v}\right)$ and forces the electron Schottky barrier height (e-SBH) above $0.5 \mathrm{eV}$ irrespective of the metal workfunction [6]. Several approaches, including dopant segregation [7], dipole formation [8], and surface treatment [9] were proposed to mitigate FLP phenomena. Recently, the use of an ultra-thin insulator between the metal and Ge showed an effective reduction of FLP but the degradation of $\rho_{c}$ due to a high tunneling resistance [10-13]. The formation of metal germanide can be another approach because the MIGS from metal dangling bond states in germanide can lead to an FLP reduction [14,15].

Ion implantation is another approach to achieving low $\rho_{c}$ and suppressing dopantdiffusion behaviors. For example, Germanium implantation before silicidation induces surface amorphization to aid an epitaxial regrowth on the semiconductor surface [16]. Carbon implantation (C-imp) has been introduced in Ni-silicide and Ni-germinide contacts to reduce contact resistivity $[17,18]$. However, $\mathrm{Ti} / \mathrm{Ge}$ contact with carbon implantation has been rarely reported.

Here, we investigated the effects of C-imp on the FLP reduction of a Ti/Ge contact and the related contact characteristics. Electrical characteristics were measured using the 
multiring-circular transmission line model (MR-CTLM) structure and Schottky barrier diode (SBD). Physical and structural properties of Ti/Ge contact with C-imp were analyzed using scanning electron microscopy (SEM), transmission electron microscopy (TEM), electron energy loss spectroscopy (EELS), and secondary ion mass spectrometry (SIMS).

\section{Materials and Methods}

N-type Ge wafers moderately doped with phosphorus $\left(\sim 10^{18} \mathrm{~cm}^{-3}\right)$ were cleaned in a 1:100 diluted HF (dHF) solution and deionized (DI) water to remove native oxide. Subsequently, $\mathrm{C}^{+}$ions were implanted into the Ge substrate at a dose of $1 \times 10^{15} \mathrm{~cm}^{-2}$ and an implantation energy of $10 \mathrm{keV}$. A reference sample without C-imp was also prepared. A SBD of Ti/Ge structure and a MR-CTLM structure were fabricated on the Ge substrate to characterize electrical properties. First, a $100 \mathrm{~nm}$ thick $\mathrm{SiO}_{2}$ was deposited to isolate the contact holes using a plasma-enhanced chemical vapor deposition (PECVD). Then, the metal contact was formed using the conventional photolithography process. Sequentially, the oxide was etched using a dry etcher, and a $\mathrm{Ti}(5 \mathrm{~nm}) / \mathrm{TiN}(5 \mathrm{~nm})$ was deposited using a DC sputtering system. After a metal lift-off process, rapid thermal annealing (RTA) was performed in $\mathrm{N}_{2}$ ambient for $60 \mathrm{~s}$ at $450-600{ }^{\circ} \mathrm{C}$. Finally, a $100 \mathrm{~nm}$ thick Al was deposited as contact pad metal. The electrical measurements of current $(I)$-bias voltage $(V)$ were performed using Keithley 4200-SCS. TEM images of the Ti/Ge structure without and with C-imp were obtained using a JEOL JEM 2200FS with an image Cs-corrector.

\section{Results}

Figure 1 shows the $J-V$ characteristics of the Ti/Ge contacts with and without C-imp at RTA temperatures in a range of $450-600{ }^{\circ} \mathrm{C}$ for $60 \mathrm{~s}$ in $\mathrm{N}_{2}$ ambient. The Ti/Ge contact without C-imp shows a typical rectifying behavior attributed to a strong FLP near the $E_{v}$, which leads to a significantly high e-SBH and reduces the reverse current density. On the other hand, the Ti/Ge contact with $\mathrm{C}$-imp shows an Ohmic-like behavior with relatively high current density under the reverse regime, indicating the alleviation of FLP.

(a)

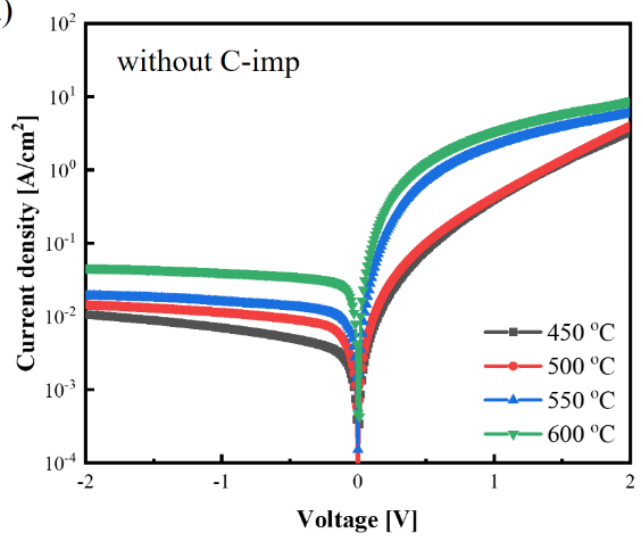

(b)

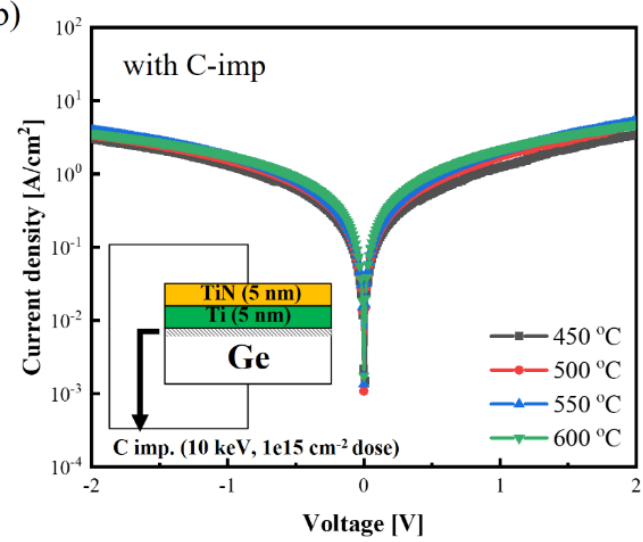

Figure 1. $J-V$ characteristics of the Ti/Ge contact (a) without and (b) with C-imp at RTA temperatures in a range of $450-600{ }^{\circ} \mathrm{C}$ for $60 \mathrm{~s}$ in $\mathrm{N}_{2}$ ambient.

Figure 2a shows the extracted e-SBHs of the Ti/Ge contacts without (blue box) and with (red box) C-imp after RTA at $550{ }^{\circ} \mathrm{C}$ and $600{ }^{\circ} \mathrm{C}$, respectively, for $60 \mathrm{~s}$ in $\mathrm{N}_{2}$ ambient. The e-SBHs were extracted from the current-temperature $(I-T)$ curves in a range of 300-378 K. The $I-V$ relationship of a Schottky barrier diode is represented by [19]

$$
I=A A^{*} T^{2} e^{-q \varnothing_{B} / k T}\left(e^{q V / n k T}-1\right)=I_{S 1} e^{-q \varnothing_{B} / k T}\left(e^{q V / n k T}-1\right)=I_{S}\left(e^{q V / n k T}-1\right)
$$


where $I_{S}$ is the saturation current, $A$ is the diode area, $A^{*}=4 \pi q k^{2} m^{*} / h^{3}=120\left(m^{*} / m\right)$ $\mathrm{A} / \mathrm{cm}^{2} \cdot \mathrm{K}^{2}$ Richardson's constant, $\Phi_{B}$ is the barrier height, and $n$ is the ideality factor. For $V \gg k T / q$ Equation (1) can be written as follows:

$$
\begin{gathered}
\ln \left(I / T^{2}\right)=\ln \left(\mathrm{AA}^{*}\right)-q\left(\varnothing_{B}-V / n\right) / k T \\
\varnothing_{B}=\frac{V}{n}-\frac{k}{q} \frac{d\left[\ln \left(I / T^{2}\right)\right]}{d(1 / T)}=\frac{V}{n}-\frac{2.3 k}{q} \frac{d\left[\log \left(I / T^{2}\right)\right]}{d(1 / T)}
\end{gathered}
$$

(a)

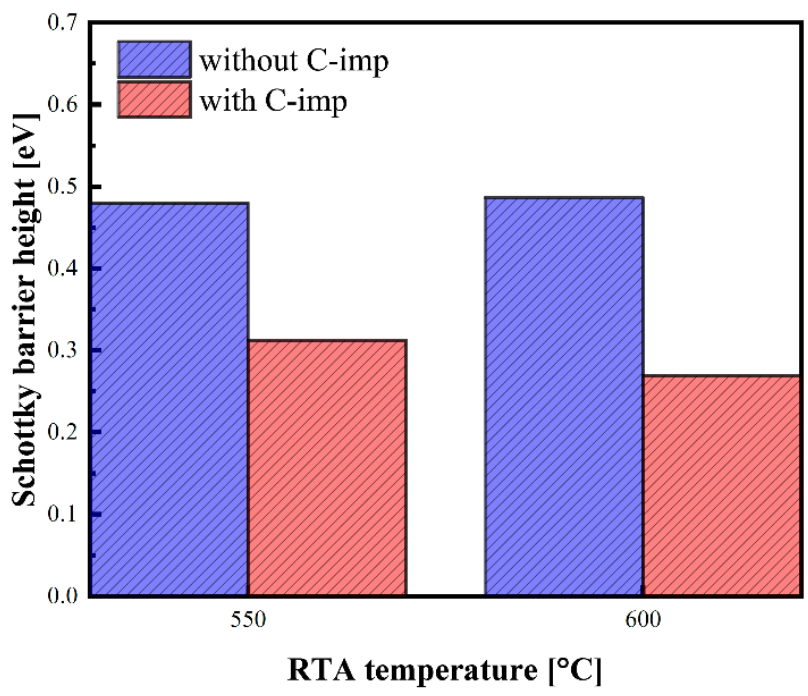

(b)

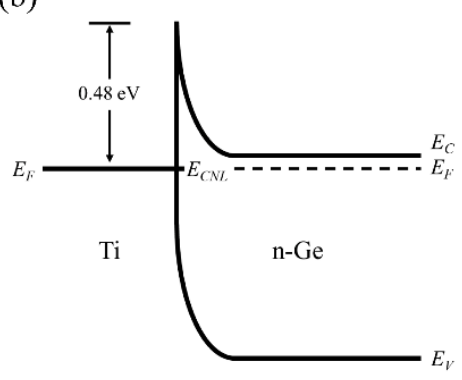

(c)

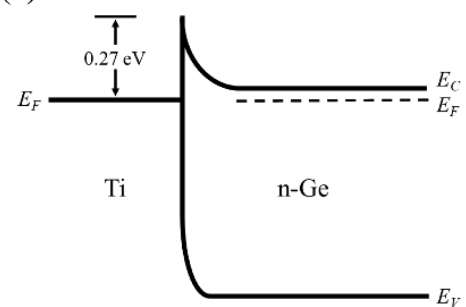

Figure 2. (a) e-SBHs of the Ti/Ge contacts without (blue box) and with (red box) C-imp after RTA at $550{ }^{\circ} \mathrm{C}$ and $600{ }^{\circ} \mathrm{C}$ for $60 \mathrm{~s}$ in $\mathrm{N}_{2}$ ambient, respectively. Schematics of energy band diagrams for $\mathrm{Ti} / \mathrm{Ge}$ contact (b) without and (c) with C-imp after RTA at $600{ }^{\circ} \mathrm{C}$.

Therefore, the barrier height is calculated from the slope $\left(=d\left[\ln \left(\mathrm{I} / T^{2}\right)\right] / d(1 / T)\right)$. The bandgap and electron affinity in $\mathrm{eV}$ of $\mathrm{Ge}$ at $300 \mathrm{~K}$ are 0.66 and $4.0 \mathrm{eV}$, respectively. The workfunction of Ti metals is about $4.3 \mathrm{eV}$. When Fermi level is pinned near $E_{v}$ of $\mathrm{Ge}, \Phi_{B}$ of $\sim 0.6 \mathrm{eV}$ is calculated. If there is negligible FLP, $\Phi_{B}$ of $\sim 0.3 \mathrm{eV}$ is obtained.

Without C-imp, the SBH of $\sim 0.48 \mathrm{eV}$ was obtained for both $550{ }^{\circ} \mathrm{C}$ and $600^{\circ} \mathrm{C}$ RTA, indicating the occurrence of FLP. In contrast, the SBH with C-imp was significantly reduced from $0.31 \mathrm{eV}$ at $550{ }^{\circ} \mathrm{C}$ to $0.27 \mathrm{eV}$ at $600{ }^{\circ} \mathrm{C}$.

Figure $2 b, c$ show schematics of the energy band diagrams for Ti/Ge contacts. Without C-imp, Fermi-level on the Ti side is pinned with the charge neutrality level $\left(E_{C N L}\right)$ due to FLP [6].

Figure 3 shows a top-view SEM image of the fabricated MR-CTLM structure to extract $\rho_{c}$ and the sheet resistance beneath the metal $\left(R_{S}\right)$. The current flows through multiple metal-semiconductor structures from the center region to the outer-circle region. From the $I-V$ curve of MR-CTLM, the total resistance $\left(R_{t o t}\right)$ is expressed as the sum of the effective resistance $\left(R_{\text {eff }}\right)$ and the parasitic resistance $\left(R_{p r}\right)$ as follows [20]:

$$
\begin{gathered}
R_{t o t}=R_{e f f}+R_{p r} \\
R_{e f f}=\frac{R_{s}}{2 \pi} \sum_{i=0}^{9}\left[\ln \left(\frac{r_{i}+S_{m}}{r_{i}}\right)+L_{t}\left(\frac{1}{r_{i}}+\frac{1}{r_{i}+S_{m}}\right)\right] \\
R_{p r}=\frac{R_{m}}{2 \pi}\left[\sum_{i=1}^{9} \ln \left(\frac{r_{i}-L_{t}}{r_{i}-S_{s}+L_{t}}\right)\right]
\end{gathered}
$$


where $r_{0} \sim r_{9}$ are the inner radius of the serial CTLM. $S_{m}$ and $S_{s}$ are the spacing among metal rings and dielectric rings, respectively. $L_{t}$ is the transfer length. $S_{s}=10 \mu \mathrm{m}, r_{0}=50 \mu \mathrm{m}$, and $S_{m}$, from 0.5 to $10 \mu \mathrm{m}$ were defined using an i-line stepper. $\rho_{c}$ was calculated from the $L_{t}$ $\left(=\sqrt{\rho_{c} / R_{s}}\right)$ which was extracted by fitting a set of $R_{t}-S_{m}$ data using Equations (4)-(6).

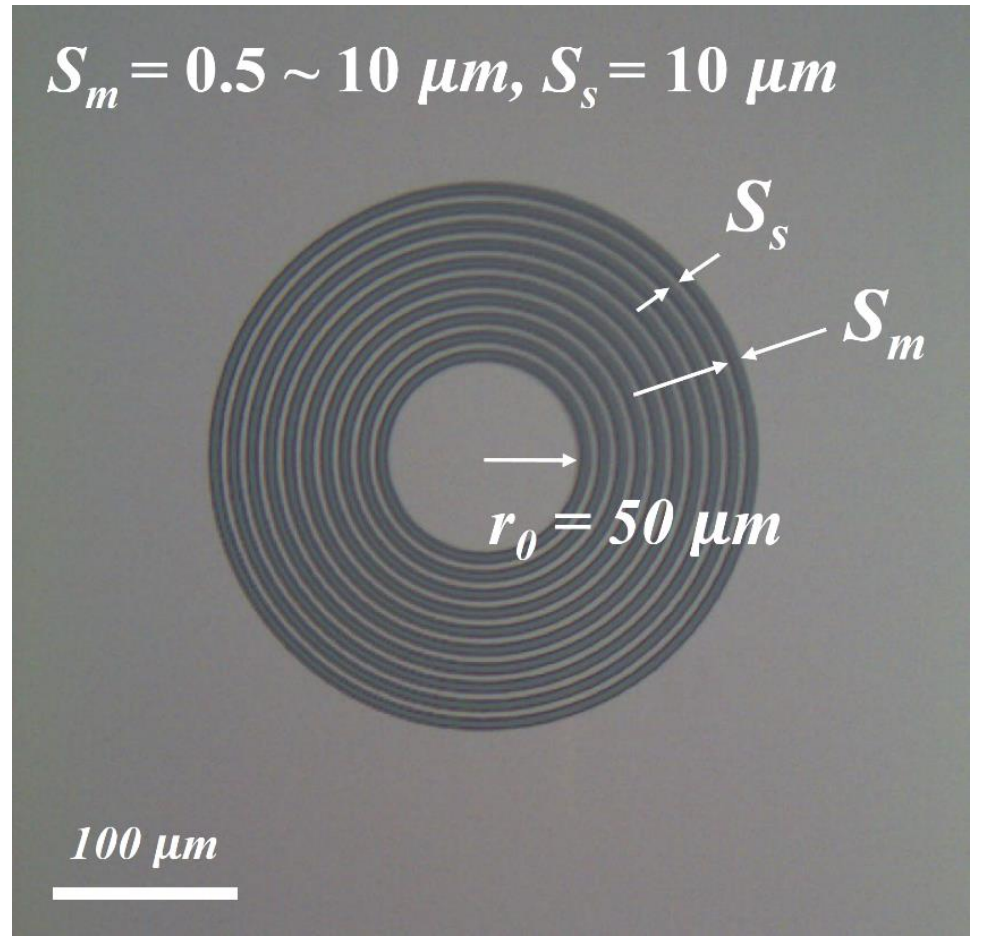

Figure 3. Top-view SEM image of the fabricated MR-CTLM structure.

Figure 4 shows the extracted $\rho_{c}$ values versus RTA temperature. $\rho_{c}$ was obtained using a MR-CTLM test structure [20]. A relatively high $\rho_{c}$ value seems mainly because of the low activation of a substrate doping concentration of $\sim 1 \times 10^{18} \mathrm{~cm}^{-3}[21,22]$. After RTA annealing at $600^{\circ} \mathrm{C}$, the $\rho_{\mathcal{C}}$ values of the Ti/Ge with and without $\mathrm{C}$ imp were $1.3 \times 10^{-5}$ and $8.4 \times 10^{-4} \Omega \cdot \mathrm{cm}^{2}$, respectively. Owing to the FLP effect, the Ti/Ge contact without C-imp shows $\rho_{c}$ values higher than $1.0 \times 10^{-4} \Omega \cdot \mathrm{cm}^{2}$.

To further analyze the effect of C-imp on the Ti/Ge composition, TEM and SIMS were conducted. The decrease of $\rho_{c}$ is mainly attributed to the dopant segregation in the Ti/Ge interface [23]. In particular, for the Ti/Ge contact with C-imp after RTA at $600{ }^{\circ} \mathrm{C}$, a further reduction of $\rho_{c}$ is observed. These results can be expected by $\mathrm{TiGe}_{\mathrm{x}}$ formation. The low resistive $\mathrm{C} 54-\mathrm{TiGe}_{\mathrm{x}}$ is formed at a temperature above $600{ }^{\circ} \mathrm{C}$ [24], which mitigates FLP and improves the contact resistivity $[14,15]$.

Figure 5a,b show SIMS profiles for Ti/Ge contacts without and with C-imp, respectively. At the $\mathrm{Ti} / \mathrm{Ge}$ interface with $\mathrm{C}$-imp, the peak $\mathrm{P}$ concentration increases from $1.6 \times 10^{18} \mathrm{~cm}^{-3}$ to $3.6 \times 10^{18} \mathrm{~cm}^{-3}$, attributed to the dopant segregation facilitated by carbon [18]. This dopant segregation can increase the tunneling current by reducing the depletion thickness at the interface and lowering the contact resistivity.

To directly observe the microstructure of Ti/Ge contact, the cross-sectional TEM images and the corresponding EELS were analyzed. The samples were prepared after RTA at $600{ }^{\circ} \mathrm{C}$ for $60 \mathrm{~s}$ in $\mathrm{N}_{2}$ ambient, as shown in Figure 6. In EELS maps, a bright region represents the area that the element of interest is abundant. With C-imp, Ge element is considerably observed in the Ti layer (red box in Figure 6b). The diffused Ge reacts with $\mathrm{Ti}$ and forms the Ti-germanide during the RTA process, which is beneficial to reduce the contact resistivity $[14,15]$. These results show that the C-imp is a promising approach to lower the contact resistivity in $\mathrm{Ti} / \mathrm{Ge}$ contact by inducing the dopant segregation and $\mathrm{Ge}$ diffusion into the Ti layer. 


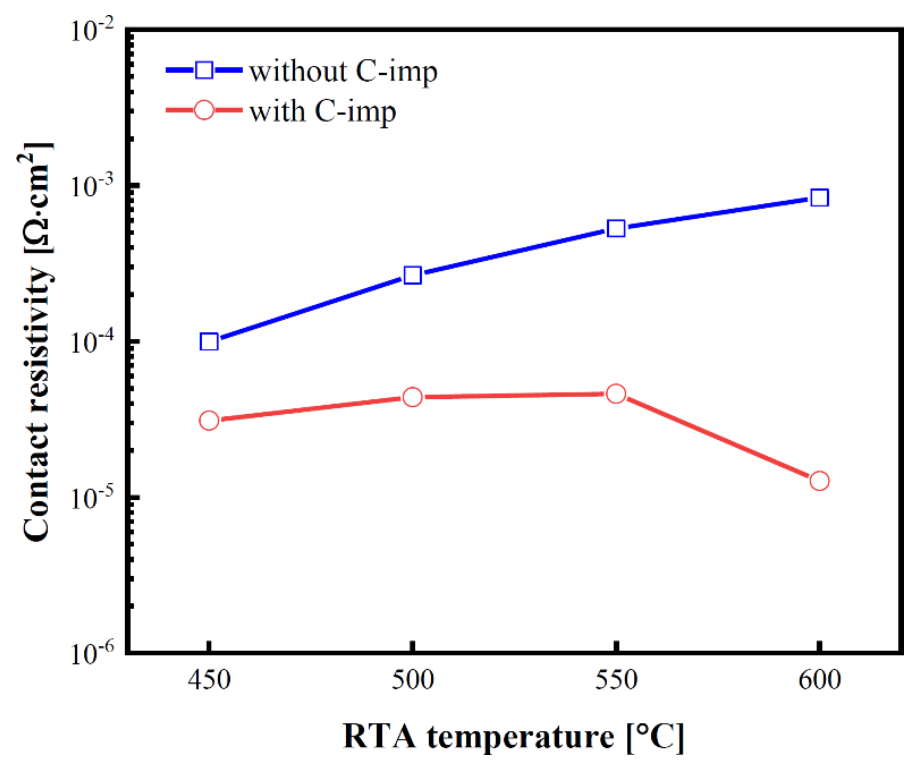

Figure 4. $\rho_{c}$ of the Ti/Ge contacts without (blue curve) and with (red curve) C-imp as a function of RTA temperatures ranging from 450 to $600^{\circ} \mathrm{C}$.

(a)

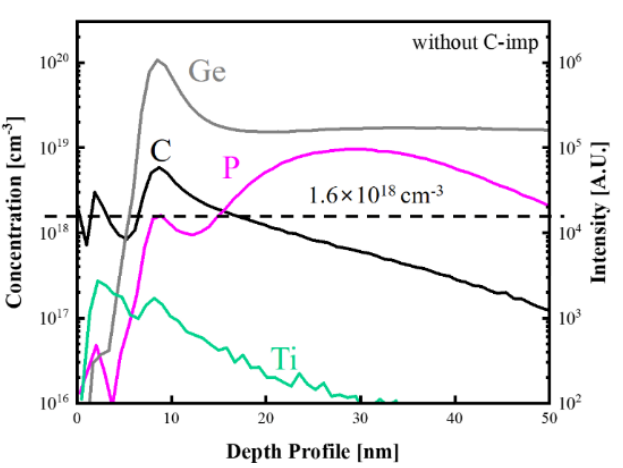

(b)

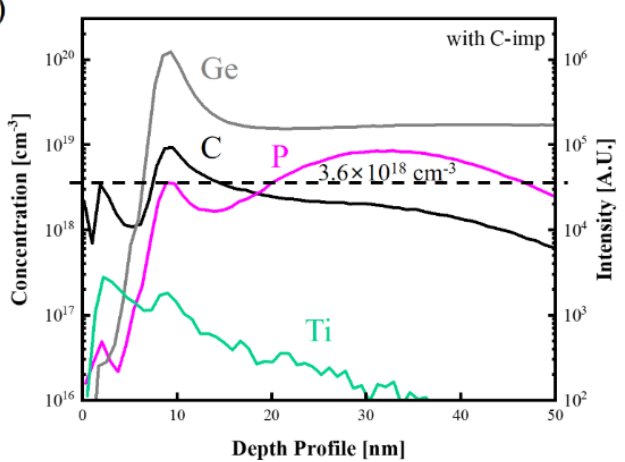

Figure 5. SIMS profiles for Ti/Ge contacts (a) without and (b) with C-imp after RTA at $600{ }^{\circ} \mathrm{C}$. With C-imp, a dopant (phosphorous) segregation at the Ti/Ge interface is clearly observed.

(a)
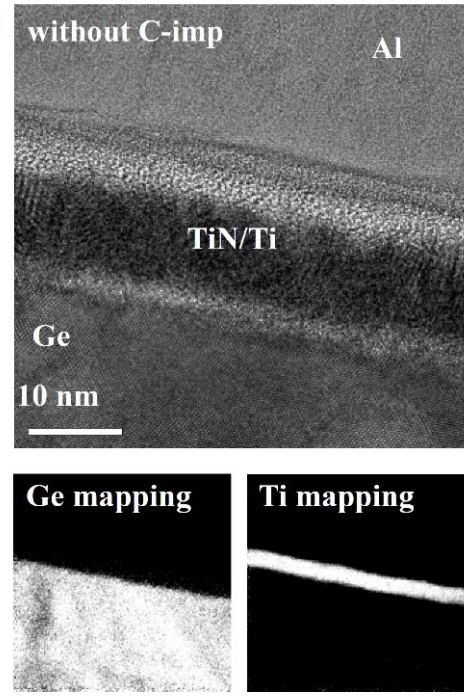

(b)
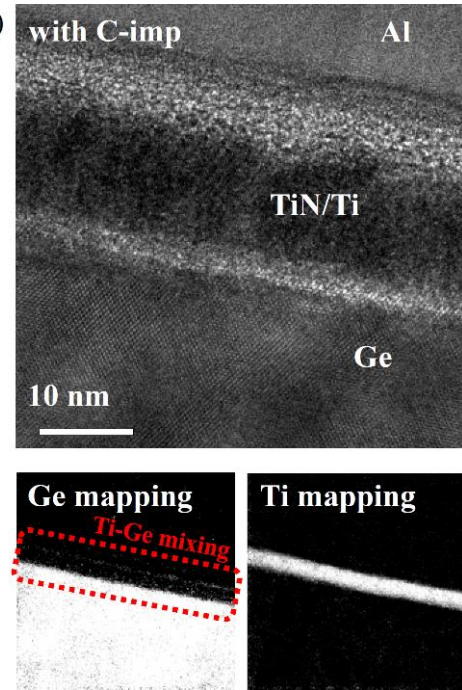

Ti mapping

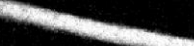

Figure 6. Cross-sectional TEM images and corresponding electron energy loss spectroscopy (EELS) mapping images for $\mathrm{Ge}$ and $\mathrm{Ti}$ in the Ti/Ge contacts (a) without and (b) with C-imp after RTA at $600{ }^{\circ} \mathrm{C}$. 


\section{Conclusions}

We investigated the electrical and material characteristics of a Ti/Ge contact with C-imp. The current-voltage behavior shows that the carbon implantation changes the $\mathrm{Ti} / \mathrm{Ge}$ rectifying behavior into an Ohmic-like behavior above RTA at $450{ }^{\circ} \mathrm{C}$. The extracted Schottky barrier height was also decreased due to the mitigation of Fermi-level pinning. The specific contact resistivity of the $\mathrm{Ti} / \mathrm{Ge}$ contact with C-imp was significantly reduced by approximately two orders of magnitude. Transmission electron microscopy and secondary ion mass spectrometry showed that carbon element at the Ti/Ge interface facilitates the dopant segregation and induces the diffusion of Ge into Ti layer. Therefore, the carbon implantation is promising to improve the Ti/Ge contact properties for high-performance Ge-FET applications.

Author Contributions: Conceptualization, I.P.; investigation, D.L.; methodology, J.K.; data curation, B.J.; writing-original draft preparation, I.P. and J.-S.L.; writing-review \& editing, I.P. and J.-S.L.; supervision, J.-S.L. All authors have read and agreed to the published version of the manuscript.

Funding: This work was supported by the Future Semiconductor Device Technology Development Program (10067739), funded by Ministry of Trade, Industry \& Energy (MOTIE) and Korea Semiconductor Research Consortium (KSRC) and by Food, Agriculture, Forestry, and Fisheries (IPET) through the Animal Disease Management Technology Development Program, which is funded by the Ministry of Agriculture, Food, and Rural Affairs (MAFRA) (120091-02-1-CG000) and by National R\&D Program through the National Research Foundation of Korea (NRF) funded by Ministry of Science and ICT (2020M3H2A1078045).

Conflicts of Interest: The authors declare no conflict of interest.

\section{References}

1. Simoen, E.; Claeys, C. Germanium-Based Technologies, 1st ed.; Elsevier: Oxford, UK, 2007; pp. 67-96.

2. Mönch, W. Barrier heights of real Schottky contacts explained by metal-induced gap states and lateral inhomogeneities. J. Vac. Sci. Technol. B 1999, 17, 1867-1876. [CrossRef]

3. Nishimura, T.; Kita, K.; Toriumi, A. Evidence for strong Fermi-level pinning due to metal-induced gap states at metal/germanium interface. Appl. Phys. Lett. 2007, 91, 123123. [CrossRef]

4. Tersoff, J. Schottky barriers and semiconductor band structures. Phys. Rev. B 1985, 32, 6968-6971. [CrossRef] [PubMed]

5. Robertson, J.; Guo, Y.; Zhang, Z.; Li, H. Extending the metal-induced gap state model of Schottky barriers. J. Vac. Sci. Technol. B 2020, 38, 042208. [CrossRef]

6. Dimoulas, A.; Tsipas, P.; Sotiropoulos, A.; Evangelou, E.K. Fermi-level pinning and charge neutrality level in germanium. Appl. Phys. Lett. 2006, 89, 252110. [CrossRef]

7. Tong, Y.; Liu, B.; Lim, P.S.Y.; Yeo, Y. Selenium Segregation for Effective Schottky Barrier Height Reduction in NiGe/n-Ge contacts. IEEE Electron Device Lett. 2012, 33, 773-775. [CrossRef]

8. Wang, J.; Huang, W.; Xu, J.; Li, J.; Huang, S.; Li, C.; Chen, S. Schottky barrier height modulation effect on n-Ge with TaN contact. Mater. Sci. Semicond. Process. 2019, 91, 206-211. [CrossRef]

9. Kim, G.; Kim, J.; Kim, S.; Jo, J.; Shin, C.; Park, J.; Saraswat, K.C.; Yu, H. Specific Contact Resistivity Reduction Through Ar Plasma-Treated $\mathrm{TiO}_{2-\mathrm{x}}$ Interfacial Layer to Metal/Ge Contact. IEEE Electron Device Lett. 2014, 35, 1076-1078. [CrossRef]

10. Yang, J.C.; Huang, H.F.; Li, J.H.; Lee, Y.J.; Wang, Y.H. Nitrogen plasma treatment of a $\mathrm{TiO}_{2}$ layer for MIS ohmic contact on n-type Ge substrate. Vacuum 2020, 171, 108996. [CrossRef]

11. Shine, G.; Saraswat, K. Analysis of Atomistic Dopant Variation and Fermi Level Depinning in Nanoscale Contacts. IEEE Trans. Electron Devices 2017, 64, 3768-3774. [CrossRef]

12. Agrawal, A.; Lin, J.; Zheng, B.; Sharma, S.; Chopra, S.; Wang, K.; Gelatos, A.; Mohney, S.; Datta, S. Barrier height reduction to $0.15 \mathrm{eV}$ and contact resistivity reduction to $9.1 \times 10^{-9} \Omega-\mathrm{cm}^{2}$ using ultrathin $\mathrm{TiO}_{2-\mathrm{x}}$ interlayer between metal and silicon. In Proceedings of the 2013 Symposium on VLSI Technology, Kyoto, Japan, 11-13 June 2013; pp. 200-201.

13. Dev, S.; Meena, M.; Vardhan, P.; Lodha, S. Statistical Simulation Study of Metal Grain-Orientation-Induced MS and MIS Contact Resistivity Variability for 7-nm FinFETs. IEEE Trans. Electron Devices 2018, 65, 3104-3111. [CrossRef]

14. Lin, L.; Guo, Y.; Robertson, J. Metal silicide Schottky barriers on Si and Ge show weaker Fermi level pinning. Appl. Phys. Lett. 2012, 101, 052110. [CrossRef]

15. Zhang, Z.; Guo, Y.; Robertson, J. Origin of Weaker Fermi level Pinning and Localized Interface States at Metal Silicide Schottky Barriers. J. Phys. Chem. C 2020, 124, 19698-19703. [CrossRef]

16. Yu, H.; Schaekers, M.; Rosseel, E.; Peter, A.; Lee, J.-G.; Song, W.-B.; Demuynck, S.; Chiarella, T.; Ragnarsson, L.-A.; Kubicek, S.; et al. $1.5 \times 10^{-9} \Omega \cdot \mathrm{cm}^{2}$ Contact Resistivity on Highly Doped Si:P Using Ge Pre-amorphization and Ti Silicidation. In Proceedings of the 2015 IEEE International Electron Devices Meeting (IEDM), Washington, DC, USA, 7-9 December 2015. 
17. Park, I.; Seol, J.-B.; Yoon, G.; Lee, J.-S. Three-dimensional imaging of carbon clusters in thermally stable nickel silicides by carbon pre-implantation. Appl. Surf. Sci. 2021, 539, 148152. [CrossRef]

18. Duan, N.; Luo, J.; Wang, G.; Liu, J.; Simoen, E.; Mao, S.; Radamson, H.; Wang, X.; Li, J.; Wang, W.; et al. Reduction of NiGe/n- and p-Ge Specific Contact Resistivity by Enhanced Dopant Segregation in the Presence of Carbon During Nickel Germanidation. IEEE Trans. Electron Devices 2016, 63, 4546-4549. [CrossRef]

19. Schroder, D.K. Semiconductor Material and Device Characterization, 3rd ed.; John Wiley \& Sons: Hoboken, NJ, USA, 2015.

20. Yu, H.; Schaekers, M.; Schram, T.; Rosseel, E.; Martens, K.; Demuynck, S.; Horiguchi, N.; Barla, K.; Collaert, N.; De Meyer, K. Multiring Circular Transmission Line Model for Ultralow Contact Resistivity Extraction. IEEE Electron Device Lett. 2015, 36, 600-602. [CrossRef]

21. Ahn, H.J.; Moon, J.; Seo, Y.; Lee, T.I.; Kim, C.-K.; Hwang, W.S.; Yu, H.-Y.; Cho, B.J. Formation of low-resistivity nickel germanide using atomic layer deposited nickel thin film. IEEE Trans. Electron Devices 2017, 64, 2599-2603. [CrossRef]

22. Chou, C.; Tsai, Y.; Hsu, C.; Jau, Y.; Lin, Y.; Yeh, W.; Chien, C. Experimental realization of thermal stability enhancement of nickel germanide alloy by using TiN metal capping. IEEE Trans. Electron Devices 2017, 64, 2314-2320. [CrossRef]

23. Ku, K.C.; Nieh, C.F.; Gong, J.; Huang, L.P.; Sheu, Y.M.; Wang, C.C.; Chen, C.H.; Chang, H.; Wang, L.T.; Lee, T.L.; et al. Effects of germanium and carbon coimplants on phosphorus diffusion in silicon. Appl. Phys. Lett. 2006, 89, 112104. [CrossRef]

24. Lai, J.B.; Chen, L.J. Effects of composition on the formation temperatures and electrical resistivities of C54 titanium germanosilicide in Ti-Si ${ }_{1-x} \mathrm{Ge}_{x}$ systems. J. Appl. Phys. 1999, 86, 1340-1345. [CrossRef] 